\title{
Correction: Reactive Green 5-Decorated Polyacrylamide/Chitosan Cryogel: an Affinity Matrix for Catalase
}

\author{
${\text { Rukiye } \text { Yavaşer }^{1} \text { • Arife Alev Karagözler }}^{1}$ \\ Published online: 3 August 2020 \\ C) Springer Science+Business Media, LLC, part of Springer Nature 2020
}

\section{Correction to: Applied Biochemistry and Biotechnology https://doi.org/10.1007/s12010-020-03393-9}

The original version of this article unfortunately contained a mistake. These corrections are enumerated below.

- The section heading "Fabrication and Characterization of RG5-Attached (polyacrylamide/ alginate) Cryogels (RG5-PACH)" should read as:

Fabrication and Characterization of RG5-Attached Polyacrylamide/Chitosan Cryogels (RG5-PACH)

- The fifth sentence in the "Conclusion" section should read as:

Catalase was adsorbed on RG5-attached polyacrylamide/chitosan cryogel for the first time by the current study.

- In Table 1 , the heading $K_{\mathrm{f}}\left(\mathrm{mg} \mathrm{mL}^{-1}\right)$ should read as: $K_{\mathrm{f}}\left(\mathrm{mg} \mathrm{g}^{-1}\right)$

Publisher's Note Springer Nature remains neutral with regard to jurisdictional claims in published maps and institutional affiliations.

The online version of the original article can be found at https://doi.org/10.1007/s12010-020-03393-9

Rukiye Yavașer

ryavaser@gmail.com

Arife Alev Karagözler

akaragozler@gmail.com

1 Chemistry Department, Faculty of Arts and Sciences, Aydın Adnan Menderes University, 09010 Aydın, Turkey 